\title{
Rockwood grade I and II acromioclavicular injuries: as benign as commonly believed?
}

\author{
ALEXANDER SCOTT NORTH
}

Ninewalls Hospital and Medical School, Dundee, UK

\begin{abstract}
The acromioclavicular (AC) joint is the articulation between the distal clavicle and the acromion process of the scapula. As the upper limb moves, passive motion of the AC joint occurs in three planes, with the AC and coracoclavicular ligaments providing stability. Injuries are common, particularly during contact sports, and are classified using Rockwood's system. Grade I (sprain) and II (rupture) injuries only affect the AC ligaments and are generally managed conservatively. However, recent reports have indicated that long-term outcomes after these injuries are poor, perhaps due to an inadequate period of immobilization preventing complete ligamentous healing.
\end{abstract}

\section{Introduction}

The acromioclavicular (AC) joint is a small synovial plane joint that forms part of the shoulder complex. Proper motion at the AC joint is necessary for a good range of scapular motion, and is essential to allow proper upper limb function. The AC ligaments prevent excessive translation of the clavicle in relation to the scapula in the horizontal plane, whilst the coracoclavicular (CC) ligaments provide stability in the vertical plane (1). During upper limb motion, stability of the AC joint is maintained by the synchronous actions of the AC and CC ligaments (2).

The location of the AC joint at the lateral aspect of the shoulder girdle leaves it susceptible to injury.

\section{Corresponding Author:}

Alexander Scott North, BMSc

Ninewalls Hospital and Medical School Dundee

DD1 95Y, Dundee, UK

E-mail: a.s.north@dundee.ac.uk
Injuries tend to result from a fall onto the point of the shoulder and are common, particularly in contact sports. Clayton and Court-Brown (3) found that injuries to the AC joint constituted almost $14 \%$ of all soft tissue injuries, although the true rate will be even higher due to their exclusion of injuries associated with fractures or dislocations. Nevertheless, their study quantifies just how common Rockwood grade I (sprain) and II (rupture) AC joint injuries are.

The literature is saturated with papers striving to find the optimal surgical reconstruction technique, or trying to determine the appropriate management of grade III injuries. Conversely, very little attention is paid to grade I and II injuries, with low grade injuries being deemed benign and managed expectantly. However, are these injuries truly as innocuous as is commonly believed? This paper aims to review the data on the outcomes of grade I and II AC joint injuries and to determine whether current management of them is sufficient.

\section{Management of Rockwood grade I and II injuries}

In 1963 Tossy et al. (4) introduced the first coherent management pathway for AC joint injuries, in which they postulated that grade I and II injuries did not merit surgical intervention and should be managed conservatively. They advocated 3 weeks of sling immobilization for grade I injuries, while for grade II ones, they recommended 6 weeks in a plaster cast to maintain the arm in $60^{\circ}$ of abduction with the elbow at $45^{\circ}$. They found that these methods produced excellent long-term results, but their sample sizes were only one and two cases, respectively.

More recently, three studies (5-7) have assessed the long-term outcomes of conservative management of 
these cases (Tab. 1). The treatment methods used in these studies are all slightly different, probably due to the fact that no standardized conservative treatment pathway exists, but none implemented the spica plaster cast described by Tossy et al. (4). There is no literature comparing various methods of conservative treatment, which would allow creation of a gold-standard approach.

The long-term follow-up results of these studies were relatively poor. Shaw et al. (5) reported that at 6 months, $40 \%$ of patients had significant pain, $20 \%$ had restricted range of motion, and $11 \%$ required analgesics. At the final follow-up (20 months), 14\% had significant pain, while the injury had impacted on activities of daily living (ADL) in 9\%, 23\% had sought further treatment from their general practitioner and $29 \%$ had sought physiotherapy. These Authors noted a correlation between results at 6 months and poor final follow-up. However, it is unclear how the pain results were obtained, as pain was not directly assessed.

Mouhsine et al. (6) reported worse results, with $27 \%$ failing conservative management and requiring surgery for residual symptoms. Failure occurred at an average of 26 months, which suggests that the study by Shaw et al. (5) was too short. Mouhsine et al. (6) also reported that $29 \%$ had fair or bad subjective scores, and that $41 \%$ experienced pain on pressure, $31 \%$ residual laxity and 54\% degenerative changes.

Mikek (7) found that 54\% reported mild, occasional symptoms at 10 years that did not impact on ADL, with no patients seeking further medical therapy. This Author found that functional outcome of the injured side was significantly lower across all three scoring systems implemented. Furthermore, in subjects with grade II injuries, joint displacement was significantly greater

Table 1. Summary of methods in papers assessing long-term outcomes of grade I and II AC joint injuries managed conservatively.

\begin{tabular}{|c|c|c|c|c|}
\hline Study & No. of patients & Average follow-up & Outcomes assessed & Treatment \\
\hline Shaw et al. (5) & 35 & 20 months & $\begin{array}{l}\text { Duration of analgesia } \\
\text { Duration of medical treatment } \\
\text { Range of medical } \\
\text { treatment } \\
\text { Subjective scores for: } \\
\text { - Disability } \\
\text { - Inconvenience } \\
\text { - Adaptation }\end{array}$ & $\begin{array}{l}\text { Broad arm sling for } 3 \text { weeks } \\
\text { Analgesia advice } \\
\text { Option to seek further therapy from } \\
\text { GP or physiotherapy }\end{array}$ \\
\hline Mouhsine et al. (6) & 33 & 6.3 years & $\begin{array}{l}\text { Activities of daily living } \\
\text { Occupation change } \\
\text { Athletic activities } \\
\text { Constant score } \\
\text { Joint laxity } \\
\text { Pain on palpation } \\
\text { Cross-body test } \\
\text { Radiographs }\end{array}$ & $\begin{array}{l}\text { Ice } \\
\text { Analgesics } \\
\text { Sling: } 1 \text { week (Grade I) and } 18 \text { days } \\
\text { (Grade II) } \\
\text { Unspecified rehabilitation }\end{array}$ \\
\hline Mikek (7) & 23 & 10.2 years & $\begin{array}{l}\text { Pain level } \\
\text { Painful clicking } \\
\text { Feeling of instability } \\
\text { Constant score } \\
\text { UCLA Shoulder Scale } \\
\text { Simple Shoulder Test } \\
\text { Ultrasound assessment: } \\
\text { - Displacement } \\
\text { - Joint space }\end{array}$ & $\begin{array}{l}\text { Sling (Unspecified time) } \\
\text { Rest } \\
\text { Ice } \\
\text { Oral analgesia } \\
2-3 \text { week rehabilitation program } \\
\text { to strengthen scapular stabilizers } \\
\text { and rotator cuff. Advised to } \\
\text { continue exercise }\end{array}$ \\
\hline
\end{tabular}


on the injured than on the contralateral, uninjured side. All three papers demonstrated that grade I and II injuries can have a considerable long-term impact on patients. Shaw et al. (5) assessed their patients through postal questionnaires, which precluded physical examinations (these, instead, were performed in the other two studies). Their finding that outcome can be predicted from findings at 6 months is interesting, as a system to identify poor outcomes would be of use for further research. Perhaps the best results were obtained by Mikek (7), who implemented the most extensive rehabilitation program; nevertheless half of their subjects still had mild symptoms at 10 years. It cannot be concluded that the rehabilitation program improved the outcomes, but the results suggest that this hypothesis should be investigated.

Mouhsine et al. (6) reported high degrees of residual laxity. A relationship exists between instability and poor outcomes in higher grade injuries $(8,9)$. Perhaps failure to allow healing of the AC ligaments following injury results in a degree of instability and altered joint kinematics (2), contributing to unsatisfactory outcomes. This hypothesis is supported by the finding of increased joint displacement (7).

There seems to be an assumption that grade I and II injuries are relatively innocuous, but the evidence shows that this is not the case. It seems unlikely that surgery would improve outcomes in grade I and II injuries, but current conservative approaches are inadequate. Perhaps reverting to plaster cast immobilization may improve results, or it may be that rehabilitation requires optimization. Variables such as duration of sling use, as well as rehabilitation programs, duration and timing of commencement could be assessed in future work. It can be concluded that current management is inadequate, and future work needs to seek to establish an evidence-based treatment pathway.

\section{Conclusions}

For many years, there were limited data on the outcomes of grade I and II AC joint injuries. Recent papers assessing results in these patients have suggested that outcomes are unsatisfactory. The results of these papers suggest that future work should look to determine a coherent management pathway, with suitable periods of immobilization and rehabilitation, so as to allow proper healing of the AC ligament complex and thus adequately prevent instability.

\section{References}

1. Fukuda K, Craig EV, An K, et al. Biomechanical study of the ligamentous system of the acromioclavicular joint. J Bone Joint Surg Am. 1986;68:434-440.

2. Oki S, Matsumura N, Iwamoto W, et al. The function of the acromioclavicular and coracoclavicular ligaments in shoulder motion: a whole cadaver study. Am J Sports Med. 2012;40: 2617-2626.

3. Clayton RA, Court-Brown CM. The epidemiology of musculoskeletal tendinous and ligamentous injuries. Injury. 2008;39: 1338-1344.

4. Tossy JD, Mead NC, Sigmond HM. Acromioclavicular separations: useful and practical classification for treatment. Clin Orthop Relat Res. 1963;28:111-119.

5. Shaw MB, McInerney JJ, Dias JJ, et al. Acromioclavicular joint sprains: the post-injury recovery interval. Injury. 2003;34:438-442.

6. Mouhsine E, Garofalo R, Crevoisier X, et al. Grade I and II acromioclavicular dislocations: results of conservative treatment. J Shoulder Elbow Surg. 2003;12:599-602.

7. Mikek M. Long-term shoulder function after type I and II acromioclavicular joint disruption. Am J Sports Med. 2008; 36:2147-2150.

8. Blazar PE, Iannotti JP, Williams GR. Anteroposterior instability of the distal clavicle after distal clavicle resection. Clin Orthop Relat Res. 1998;(348):114-120.

9. Scheibel M, Dröschel S, Gerhardt C, et al. Arthroscopically assisted stabilization of acute high-grade acromioclavicular joint separations. Am J Sports Med. 2011;39:1507-1516. 